\title{
Exploring the praxis of occupational therapy-community development practitioners
}

\author{
Abstract \\ Background. A growing body of occupational therapy knowledge and practice focuses not \\ on health but on social transformation, and couples occupational therapy with community \\ development. A tension in both these fields is the disconnect between what practitioners \\ espouse and what they do, limiting the potential of practice. To address this, practitioners are \\ encouraged to engage in praxis - the critical synthesis of theory and practice. Purpose. To \\ explore whether and how Australian occupational therapy-community development \\ practitioners engage in critical praxis. Method. A critical dialogical method was employed to \\ complete multiple in-depth interviews with four occupational therapy-community \\ development practitioners. Interviews were transcribed and analysed using thematic analysis.
} Findings. Practitioners appeared capable of praxis but were not consistently employing it. Findings were grouped into themes: disjointed praxis; authentic praxis; supporting praxis; and praxis challenges and solutions. Implications. Occupational therapists need to be supported to develop, use, and maintain skills in critical praxis.

Keywords: critical occupational therapy, occupational justice, social occupational therapy, social transformation, professional practice.

\section{Introduction}

A growing body of occupational therapy knowledge and practice focusses not on health but on justice, rights, and social transformation for groups and communities, and in doing so brings together aspects of community development and occupational therapy. A tension exists in both fields, however, between the social justice that practitioners espouse, and their real-life practice. This can limit the transformative potential of practice. To address this, practitioners have been encouraged to engage in critical praxis (Farias \& Laliberte Rudman, 2019a; Kinsella \& Whiteford, 2009; Ledwith, 2016), where theory and practice, action and 
reflection, are critically synthesised and constantly evolving (Freire, 1972). Despite this, no research to date has explored whether/how occupational therapists or community development practitioners engage in critical praxis, nor ways they may be supported to do so. This study aimed to fill this particular gap by exploring the praxis of Australian occupational therapy-community development practitioners, with the hope findings may provide insights into how to improve practice directed towards social justice.

\section{Background}

An expanding field of occupational therapy operates outside the health sphere, with a focus not on health but on social and occupational justice. Such work has been labelled 'social occupational therapy' (Lopes \& Malfitano, 2021), 'occupation-based social transformative work' (Farias \& Laliberte Rudman, 2019a) and 'critical occupational therapy' (Hammell \& Iwama, 2012; Whiteford et al., 2017). Whilst a comprehensive exploration of social justice is outside this paper's scope, it is defined here as the structuring of society to ensure just and equitable access to resources and conditions for all people, regardless of difference, to live lives they value (Ledwith, 2016; Sen, 1999). Complementary to this is occupational justice, the recognition that that all people have a right to fair and equitable opportunities to do the things they need, want and have to do (Hocking, 2017). As social occupational therapy's focus is on justice, practitioners of this field often do not work within health services, where the focus is rehabilitation or health, rather than justice. Instead, they work across micro, meso and macro levels of society with groups, communities, and populations whose occupational challenges are seen more accurately as resulting from societal factors (e.g. discourses, practices, systems, and structures) and subsequently, as matters of justice. It is these root-causes of injustice that social occupational therapy seeks to transform, to increase possibilities for social and occupational justice (Malfitano \& Lopes, 
2018). This is often enacted through participatory processes aligned closely with community development (see Galvaan, 2017; Lopes \& Malfitano, 2021).

In its broadest sense, community development is a practice which works collectively with communities of people to raise their consciousness of systems that oppress them, and seek possibilities for challenging such systems to advance social justice (Ledwith, 2016). To achieve this, practitioners work in whatever capacity the community needs, to enable collective identification of assets and issues. Together they develop assets, and analyse the root causes of issues, deciding on and implementing initiatives needed to address them (Ledwith, 2016; Westoby \& Ingamells, 2012). People (micro) and their community (meso) are therefore central to community development practice. Simultaneously, however, community development practice works to effect change at the societal (macro) level. Considering links between the personal and political is essential for transformative outcomes focused on social justice (Ife, 2016; Ledwith, 2016). Such considerations require critical social theories, which assist practitioners to analyse power, inequality, and structural disadvantage (Ife, 2016; Purcell, 2011).

Both social occupational therapy and community development are clear in their aspirations to engage in practice that is transformative compared to ameliorative, liberating compared to pathologising, working from micro to macro, to disrupt systems and structures of injustice rather than just alleviate symptoms (Farias et al., 2016; Ledwith \& Springett, 2010). Yet enacting this vision has been recognised within both disciplines as fraught with tensions (Farias et al., 2016; Ife, 2016; Ledwith, 2016), with practitioners challenged to practice what they espouse (Farias \& Laliberte Rudman, 2019a; Purcell, 2011; Quiroga \& Reyes, 2019; Shaw, 2017; Townsend \& Marval, 2013).

Both practice areas posit that for practitioners to realise the social transformation they espouse requires critical reflexivity and critical dialogue, to question how theories and 
assumptions promote rather than challenge the status quo, and similarly, to resist ways practice may be co-opted by the very structures and ideologies they aspire to challenge (Farias \& Laliberte Rudman, 2019a; Kinsella \& Whiteford, 2009; Ledwith, 2016; Quiroga \& Reyes, 2019; Townsend \& Marval, 2013). Such elements come together in critical praxis (Ledwith, 2016).

Freire (1972) described praxis as the unity of critical reflection and action, theory and practice, to transform the world, and stipulated such praxis was only authentic when its subsequent actions again became the focus of critical reflection. This integrated cycle of action and critical reflection, where theory is simultaneously generated in action and action from that theory, becomes a 'way of being', a critical living praxis, that is more than mere theory-practice congruency (Ife, 2016; Ledwith, 2016). Within such praxis, 'theory' is not merely an abstract concept but is unveiled in concrete situations and everyday life (Freire, 1972). Integral to this are critical dialogue and reflexivity (Ledwith, 2016). Critical dialogue is not just an exchange of ideas or stories, but a participatory process where individuals communicate as equals in a process of critical inquiry about what is being shared, to unify theory and everyday action (Freire, 1972; Ife, 2016). Critical reflexivity is more than reflection (Farias et al., 2016). It is the process of critically reflecting on our reflections to interrogate unconscious attitudes, assumptions and positions of power influencing how/why we act in the world the way we do (Kinsella \& Whiteford, 2009; Ledwith, 2016), under the premise that acting critically requires seeing critically (Freire, 1972). Such skills assist practitioners to question taken-for-granted aspects of oppression, and understand its structural causes (Freire, 1972). Without critical reflexivity, we risk engaging in thoughtless action, or meaningless activism (Kinsella, 2001). Similarly, failure to act on our reflexivity risks engaging in mere armchair revolution, or actionless thought (Ledwith, 2016). Engaging in praxis, a continual and cyclical process of questioning theoretical assumptions in light of 
practice and vice versa, is therefore essential to achieving social transformation (Freire, 1972).

Whilst we acknowledge scholars in community development, occupational therapy, and occupational science have explored utilising various critical theories to advance transformative agendas, it appears none have investigated the use of praxis as a means to do so. Rather than conceptualising praxis as something to consider in isolation from other critical theories, it is instead proposed as the vehicle through which critical theories and everyday practice (and life) can be integrated. In this sense it is purported to be essential for practitioners to enact their vision of advancing social justice (Freire, 1972; Kinsella \& Whiteford, 2009; Ledwith, 2016). To our knowledge, neither occupational therapy nor community development have engaged in research exploring practitioners' use (or lack thereof) of such praxis. We aimed to address this gap by exploring the question: "What are the experiences of engaging in critical praxis among Australian occupational therapycommunity development practitioners?"

Australia was chosen for both convenience (two of the authors reside in Australia) and to contribute to the limited body of research on this practice area in Australia. To date no studies have investigated social occupational therapy within Australia, although we acknowledge the literature on occupational justice, and occupational therapy-community development practice in the Australian context (see Hyett et al., 2018; Whiteford et al., 2018).

\section{Method}

It was essential the study's methodology clearly aligned with values and aims of social occupational therapy (Malfitano \& Lopes, 2018), community development, and Freirean praxis (Ledwith, 2016): equity, empowerment, trust, dignity, and working with rather than on people. A critical dialogical approach, inspired by Farias et al. (2019), was 
therefore selected. This approach is critical because it seeks to question taken-for-granted assumptions, beliefs, discourses, and practices and in doing so spark possibilities for changes in/around practices aimed at social transformation. It does this through dialogue, which for this study's purposes, was understood from Freire's perspective (1972) (discussed above). Such a collaborative process is essential to critical research, which rejects notions of valuefree truths and therefore seeks to integrate multiple views and understandings to make sense of phenomena (Kincheloe \& McLaren, 2000). A critical awareness of power relations is therefore central to this methodology, which seeks to disrupt traditional views of researcher as expert and instead views participants as co-researchers, equally responsible for making sense of experiences (Farias et al., 2019). The methodology also reflected a praxis-orientation as, through dialogue, participants and researcher critically reflected on practice, seeking to illuminate possibilities for future change.

It is important to clarify our positionality in relation to the research. We identify as white, female academics from two countries, one involved with the origins of social occupational therapy. Two of us are involved in occupational therapy education, and one in community development education. All of us have experience in community work. The research underpinning this article was motivated by ongoing discussion and reflection on synergies between community development and occupational therapy, with implications for education and practice in both fields. In particular, we were interested in Paulo Freire's idea of praxis as a channel for social transformation, and a tool for professional action.

The study had ethical approval from the institutional Human Research Ethics Committee (project number HEA-19-083).

\section{Recruitment}

To explore social occupational therapy practice in Australia (a relatively unknown field), we sought to recruit occupational therapists working in community development 
outside of health services and with communities who were not defined primarily by health diagnoses or conditions. Participants had to have completed either a bachelor or master's degree in occupational therapy and have at least two years' experience working in community development outside of health services. We hoped to recruit between five and eight participants, with each participating in two interviews. We predicted the quantity and depth of data produced from this would be sufficient to meet the study's exploratory goals, whilst also being a pragmatically manageable size within the existing timeframes.

As the practice area under investigation is niche, and known to exist on the margins of occupational therapy (Pollard \& Sakellariou, 2017), we predicted the potential participant pool would be small, and reaching such participants challenging. Convenience sampling (Newing et al., 2011) was used as a starting point. Recruitment documents outlining the study aim, and including a definition of community development, were emailed to all our networks of occupational therapy colleagues, who were encouraged to distribute these further. Two interested participants contacted the first author to participate and were recruited. Snowball sampling (Babbie, 2015) was then used as one participant facilitated recruitment of another, who subsequently facilitated recruitment of another.

\section{Participants}

Four participants volunteered and signed consent forms prior to data collection. This sample size was believed to reflect the niche area of practice. Two participants were known to the first author, although she knew little of the specifics of their work. One was a friend with whom the first author had studied, and the second was an acquaintance. This lent itself to the methodological aim of disrupting the traditional views of researcher as expert.

\section{Data Collection}

Inspired by Farias et al. (2019), each participant engaged in two separate dialogical interviews with the first author, two-four weeks apart, which were conducted online and 
recorded. The first interview involved the participant providing an account of a memorable experience in their community development work. The first author then engaged the participant in critical dialogue about the experience, exploring what knowledge, theories and reflections had informed the actions in the experience, and whether such actions had in turn been critically reflected upon, theorised about, and used to inform ongoing practice. Whilst an interview guide was drafted (see Table 1), this was used loosely as a starting point and, in keeping with the study's methodological assumptions, participants were supported to direct the conversation towards points they wished to explore.

\section{[Table 1]}

First interviews were transcribed and reviewed by the first author to stimulate a process of critical reflexivity (reflecting upon the reflections and assumptions evident in the first interview), throughout which the first author posed new questions into the original transcript. The participant was invited to respond to these questions in the transcript document (see Fig. 1) before returning it to the first author prior to the second interview. This aimed to facilitate critical reflexivity and a deeper exploration of the experience/s shared, by providing greater distance from the original experience described (Ledwith \& Springett, 2010). The second dialogical interview was then used to discuss comments and critical reflections generated from the first interview.

\section{[Figure 1]}

Two participants responded to additional questions within their first transcript, sharing this with the first author prior to the second interview. The other two participants reported reading the additional questions but chose to leave these for discussion in the second interview, rather than respond within the document. Transcripts were only shared with the participant they involved. All transcripts were professionally transcribed but checked by the first author for accuracy. 


\section{Data Analysis}

Acknowledging there is no strict formula for critical qualitative analysis (Kincheloe \& McLaren, 2000), Braun and Clarke's (2006) method of thematic analysis was used as a starting point to facilitate thorough, deep engagement with data by the first author. This was supplemented with discussions between all authors, highlighting critical points of relevance. We used a theoretical approach to generate codes related to praxis, i.e. the first author sought examples of praxis (and its component parts) from practice experiences participants shared. An inductive approach was used to generate other codes across the dataset. Data extracts for each code were collated into a separate document and collated into possible themes which were reviewed and refined with the assistance of the other authors. At multiple times throughout analysis and write-up the first author reflexively returned to the original transcripts to ensure findings accurately and coherently reflected the dataset. This was accompanied by using a research journal where the first author captured her reflexive internal dialogue to challenge 'unconscious editing' and support comprehensive engagement with data (Berger, 2013). A critical lens was employed throughout by consciously seeking to look behind codes and themes to consider deeper assumptions, discourses, taken-for-granted aspects, and/or relations of power reflected in the experiences shared.

\section{Findings}

The four participants were female with bachelor's degrees in occupational therapy from Australian universities. All had also undertaken studies in either community development, international development, anthropology, public health, or a combination thereof, at either masters or $\mathrm{PhD}$ level. To maintain anonymity, their names and detailed descriptions of their work have been omitted. All had experience in community development outside of healthcare services, ranging from two to more than twenty years. Some roles had been predominantly service-delivery, effecting change at the micro. Other roles had created 
possibilities for social transformation, often by supporting empowerment of marginalised people, intending to effect change across micro, meso and macro levels simultaneously. Participants were recruited based on experience working in community development within Australia but three also had community development experience in international settings. Collectively, they had experience working on a variety of projects (e.g. community integration, land management, access to education and housing) with refugees and asylum seekers, First Australians, and women experiencing homelessness.

To answer the question 'What are the experiences of engaging in critical praxis among Australian occupational therapy-community development practitioners?', participants all made reference to integration of theory and practice, but this seemed to span isolated instances of theory-practice/action-reflection (i.e. disjointed aspects of praxis), to cyclical integration of theory-practice/action-reflection (i.e. authentic praxis) (see Fig 2). Similarly, 'thinking about their doing' seemed to range from superficial and operational reflection to more critical, nuanced, and deeper reflection. Findings were grouped into four themes: disjointed aspects of praxis; full cycles of praxis; supporting praxis; and challenges and solutions to praxis.

\section{[Figure 2]}

\section{Disjointed Praxis}

Examples of disjointed praxis demonstrated participants' abilities to engage in some key aspects of authentic praxis, notably reflection on action and critical thinking. They did not appear, however, to consistently synthesise these, nor use these to inform ongoing practice. Whilst capable of reflecting on practice, such reflection occasionally seemed more concerned with operational matters, lacking critical depth: 
We do a debriefing questionnaire that prompts you to look at the stuff you did well, the stuff you want to do differently, the stuff you could do better on, and then you affirm yourself on the things that were fine (Participant A).

Missing was an exploration of why certain practices had been effective/ineffective, without which a more nuanced and critical understanding of practice is hard to glean. Without this critical understanding there is uncertainty around effectiveness of subsequent actions to enhance practice.

At other times practitioners demonstrated critical reflexivity and integration of critical theoretical perspectives as they unpacked contradictions in practice, yet they felt paralysed to effect changes in such practice:

We had to do [asylum seekers']... banking payment and we had to cut off the percentage - they were only given $83 \%$ of the Centrelink payment, and then if they had defaulted on any kind of payments, we took that off. Eventually I was...the person doing this to the asylum seeker... When you look back on Nazi Germany and you say, how did the guards do that?... Well, I'll be that guard. Why did I follow what these big organisations are doing?... I hated it and was, like, why am I being made to do this? ...You fall into the trap... financially I needed a job but also you rely on the top dogs doing the right thing (Participant A).

Additionally, for some participants, theory seemed to be seen only as something abstract sitting outside of practice, which other people generated, and which they had to apply to their own practice:

[Theory is] about being able to do a quick library search to see, okay, what's new since I was at uni[versity], what are the experts in this field saying, what are other people who've developed similar programs saying and how are they linking back to research? (Participant B). 
Whilst there is no denying this core aspect of effective practice, some participants did not give the same importance to generating theory from their own action, or critiquing theory in light of their practice. This was despite having the ability to do so. When prompted, all participants readily critiqued the limitations of occupational therapy theory, notably occupational therapy models, which focus primarily on the individual, with limited attention given to broader contextual factors. Participant A provided a reflection of her practice with refugees:

You can go in on your micro level and say, 'Well I helped you buy lunch and I've shown you the bus route and then that's my job done,' but up to the bigger level you're almost keeping people in a system that perpetuates stress and ill-health and segregation.

Participant D highlighted that it was only through completing a $\mathrm{PhD}$ she made this 'mental leap' of understanding the importance of critiquing theory:

That was the biggest shift in my PhD cognitively - what I'm seeing in the world has implications for shifts in theory and... we need to be ...critical of theory and shifting it, if it doesn't fit with what we're seeing. That was a very big mental leap for me. If theorising about practice is essential for praxis, and if praxis is essential for achieving transformative community development work, then this suggests participants in this study needed support to make this 'mental leap' much earlier in their training.

\section{Authentic Praxis}

Whilst fewer in number, other practice examples demonstrated authentic praxis (Freire, 1972). Whilst seemingly simple, the following demonstrates the practitioner's ability to critically reflect on her practice and position of power, and then adapt her practice, in a cycle of action and reflection, practice and theory. 
When I was doing training for community groups, there was definitely a difference, that I'm this expert, I've had all this other training and ...they must defer to me... So, when I do training, I make it as participatory as possible and get their answers to things because otherwise I feel like they take my word as gospel (Participant A). Unsurprisingly, the most experienced practitioner, who had also published and taught occupational therapy-community development, best articulated the complexity of praxis and the flexibility and responsiveness to context it requires:

The experience and ...reflection are absolutely critical and then, the problem-solving that comes with it. And it never stops... because you think - yeah, I refined this, this really works, but then it doesn't quite...there's no recipe...It's the process that counts and the mixing and matching of techniques or methods or tools or whatever and try and work out well, what's going to work best here? And how do we build on what we're finding as we go along? (Participant C).

Through discussions of her practice, she provided an example of her own authentic praxis, critiquing theory based on her experience, adapting that theory based on her own theorising, and then using it in practice:

It's an adaptation of Jess Dart's work around Most Significant Change. And...we have lots of debates... on Most Significant Change. Because some of it I don't think is that practical. So we've adapted some of those things... we've designed different ways by which we work with people to gather stories of significance. The significance might be significant change or significant learning or significant the things that went AWOL. It's about taking those stories and then we put them together and give them back to people to workshop what they think is meaningful in those stories. It's highly participatory - and it really is empowering (Participant C). 
Of significance is that two participants set up their own development organisations to escape constraints experienced when working for others, demonstrating integration of critical reflection-on-practice informing future actions (starting their own businesses):

We'd been doing a lot of work with different organisations... and... were really frustrated with the way a lot of the work was being done... We wanted to... have a go at doing some of this work the way we really wanted it. The way we thought it should be done. So...I'm in this luxury position, where I am the director...of the organisation and I have a core group of people around me... They're values-driven, rather than driven by money and power and kudos (Participant C).

\section{Supporting Praxis}

Essential is trying to understand how practitioners move from disjointed praxis to a cyclical unity of action and critical reflection, theory and practice, to achieve authentic praxis (Freire, 1972). Crucial to this is critical thinking (Ife, 2016; Ledwith, 2016), as highlighted by participants: "I think we do need to be critical of the work we do in the community sector and take time to reflect and build in mechanisms that support quality improvement" (Participant B).

Participants' own critical perspectives were evident in their reflections on positionality and use of reflexivity in their work:

You're constantly looking at... the power relation, historical context, people getting bolshy because they see a white woman who has come from, whatever... but you go away and think, that hurt but did I do something that actually was an unconscious expression of something I didn’t say quite right? (Participant C).

Yet all participants reported either by nature or by discipline, critical thinking is something occupational therapists are generally not adept at: "I worked with OT's who probably are quite good at ... [critical thinking] whereas if I look at a different context... I'm 
not so sure" (Participant B). "We're the little mice on the running wheel. We get our stuff done, we produce the outcomes, we're usually very diligent and submissive... We toe the line... we're not too outspoken or aggressive or assertive" (Participant A). Participant D shared her thoughts on potential causes of this:

I don't remember having that opportunity [to critique theory] in undergrad [occupational therapy]. I feel a lot of educators see undergrad as teaching students a thing so they can go and do a thing, and sometimes less critically... but art students are critical of absolutely everything. Maybe it's a discipline thing.

Participants reported that additional studies outside of occupational therapy assisted in developing their critical thinking: "It's probably been the more I've studied that I've become aware of the layers of power between me and a client in the community" (Participant A). Another participant added:

I've done a lot of reading around participatory community development and participatory research processes and trying to be a more critical researcher, kind of unpacked myself who gets to ask what questions and how and what I'm imposing on and what I'm allowing in (Participant D).

Writing and dialogue appeared to support critical thinking, and praxis overall. Participants identified writing as a means that assisted with different aspects of praxis synthesising critical reflection and action, and theory and practice: "Writing up the final report helps [critical reflection] - when you're actually having to write it up and look at the data in front of you it makes you be more reflective and rearrange or adjust programs going forward" (Participant A).

Dialogue with others, whether formal or informal, also assisted in generating deeper reflections about action (then used to inform new action) as well as synthesising theory and practice. Participants identified different people they would engage in dialogue (peers, 
colleagues, or supervisors); notably someone with whom they had established and trusting relationships, and who would engage critically:

We did...a massive why-why diagram... unpacked the complexity of it and...said, "Where are the opportunities, where can we shift things?" ...I was like, "Oh yeah, it's very complex. There's a lot of stuff going on here," ... to have that opportunity to reflect and to have that colleague be very open... helped me internally process a lot of that (Participant D).

The more experienced practitioner identified engaging community members in this critical dialogue, a reflection of how her individual praxis contributed to collective praxis: Every time we've got... one person...from that community who's respected... that we work with... and daily we sit down... and say, what happened here, what happened there, you tell us what we need to do differently in terms of how we managed a certain context... Often the conversation starts from an operational pragmatic perspective but very quickly, from our perspective anyway, we're interested to know, well, what's behind that... where's the power aligned, what are the politics going on here, what does that mean if we're doing this... (Participant C). Another participant highlighted the combination of critical dialogue and writing to promote critical reflexivity and direct future practice, demonstrating authentic praxis:

There was a lot of reflective work that I did with the team, it almost became habit... we would...have a big discussion around reflecting on what had happened, how does that feel for you as part of the community... With use of my reflective journal I was able to reflect and gain more of an understanding of the value these discussions brought to our work and how they would improve program outcomes ... we were able to streamline some tasks, readjust goals, plan ahead through discussion (Participant B). 
As these findings suggest, it seemed embedding these methods to support praxis within daily practice was essential:

I think [critical reflection] is now implicit and embedded, but that's supported by a real commitment to working... with the local community in processes where there's lots of...workshops to...co-design and monitor on a weekly basis what's happening, where do we go? We embed that... so that that forces reflective practice.... That helps us to continue learning ourselves and reflecting on what we've gathered and changing it as we go as well as at the end. It also forces me to do that in a more systematic way, but more importantly - it's within capacity that people are working to do that (Participant C).

\section{Challenges \& Solutions to Praxis}

Challenges to embedding and honouring such 'praxis prompts' were identified as heavy workloads, lack of funding, limited resources, organisational and professional culture, and time:

How do we genuinely build in that critical reflection on an ongoing basis [when] workloads are so heavy... and we don't ....as a profession acknowledge the critical importance of creating space each week... to critically reflect in a structured way... Seriously getting people to think about their own assumptions, their own values, to look at what that means in terms of how they engage with people and with work? (Participant C)

This same participant suggested to overcome this, practitioners needed to advocate within their organisations for prioritisation and integration of critical reflection as a foundation for praxis:

We can advocate for having at the staff meeting... critical storying. Real exercises where we take it in turns to share a story and critically reflect on it, in terms of well, 
what are we learning out of this?... We need to embed those into agendas... and get it valued in our organisations. I think we need to be doing that and the profession needs to be supporting therapists to do that (Participant C).

\section{Discussion}

This study aimed to explore whether/how Australian occupational therapy-community development practitioners engage in critical praxis. All participants appeared capable of engaging in at least some constituent parts of critical praxis, namely critical reflection on theory, but there was less evidence of consistent synthesis of such reflections with ongoing practice. Participants' reflections on challenges and solutions to praxis provide insights into how to support occupational therapists to be more praxis-oriented.

\section{Enacting Praxis}

Cyclical integration of critical perspectives with practice, and reflexivity with action, is required for ongoing, authentic praxis (Freire, 1972; Ledwith, 2016). From this study, writing and dialogue were two methods which supported praxis, and have also been highlighted by development scholars as essential to praxis (Ife, 2016; Ledwith, 2016). Both, however, must consciously challenge dominant worldviews by centring marginalised discourses, theories, communities, and individuals - which some participants sought to do through participatory processes in which dialoguing with communities was central. This requires personal commitment to ensure such practices are prioritised, remain critical, and resist becoming merely another recipe or procedure through which practitioners complacently move (Ledwith, 2016; Westoby, 2014).

As participant A alluded to, however, the reality is sometimes even those who are able to maintain critical perspectives and theorise about their practice, and who have a clear vision for their practice, find it impossible to enact that vision within organisational constraints (heavy workloads, lack of funding, and limited resources) (Purcell, 2011; Shaw, 2017). Such 
constraints are documented in the community development literature both within Australia (see Ingamells, 2010), and internationally (see Ledwith, 2016; Shaw, 2017), and within the literature on social occupational therapy (see Farias \& Laliberte Rudman, 2019b). Within such works, these barriers are often interpreted as symptoms of the neoliberal privatisation of state-run services, and the funding priorities accompanying such changes. On community development in the Australian context, Lenette and Ingamells (2015) frame this as "a chasm between funded practice versus practice grounded in theory, evidence, and ethics" (p. 92). Such a framing speaks directly to the challenges of engaging in praxis as touched on by participants.

The moral distress of this dilemma may compel occupational therapists to leave their positions rather than remain unwilling cogs in a system perpetuating injustices they seek to change. This was the reality for two participants, who started their own consultancies to practice what they espoused. This suggests their commitment to authentic praxis was not sufficient to influence structures they had worked within, to then practice in the way they envisioned, a finding also reflected in the literature (Purcell, 2011; Shaw, 2017; Westoby, 2014; Westoby \& Ingamells, 2012). This suggests authentic or critical praxis is not itself sufficient for achieving transformative practice, as some scholars seem to suggest (Farias et al., 2016; Freire, 1972; Kinsella \& Whiteford, 2009; Ledwith, 2016; Purcell, 2011). Further investigation of this dilemma is therefore warranted, with the hope it may illuminate ways to better support practitioners to navigate it.

\section{Models}

This study also raises questions regarding the utility of theoretical models in occupational therapy practice aimed at social transformation. Whilst models are designed to help theorise practice and make sense of complicated, multifactorial situations, we question whether the complexity of the contextualised nature of peoples' everyday lives (i.e. the site of 
occupational therapy practice) can be sufficiently captured through a model. Framing situations through models risks simplifying something that should not and cannot be simplified. Moreover, there is growing critique of the culturally specific nature of dominant occupational therapy models, developed in the Global North and influenced by Western views of health and illness, with a focus predominantly on the individual and insufficient attention given to contextual factors influencing occupational performance and engagement, and therefore occupational justice (Galvaan, 2017; Hammell, 2020). It seems occupational therapy models are therefore not fit for purpose in occupational therapy practice aimed at social transformation, where the focus is on contexts rather than individuals, and justice rather than health. We propose occupational therapy aimed at social transformation should instead be grounded in diverse knowledge bases (Galvaan, 2017) and critical perspectives (Hammell, 2020). These are integrated with practice through critical praxis processes which centre the marginalised communities (and their discourses and knowledges) they aim to serve.

\section{Critical Thinking}

From the perspective of praxis, critical thinking is employed to synthesise theory and practice, action and reflection, to promote possibilities for practice to become transformative, under the premise that to act critically we need to see critically (Freire, 1972). Whilst participants highlighted the need to remain critical within their work, they acknowledged occupational therapists are generally not adept at thinking critically, a finding reflected elsewhere in the literature (Hammell, 2020; Kinsella \& Whiteford, 2009). Such lack of criticality is believed to be due in part to educational programs where students are taught to unquestioningly accept theory as truth (Hammell, 2020; Kinsella \& Whiteford, 2009). Such processes can socialise students to become a docile and submissive professional, one at risk of complicitly maintaining hegemonies that should instead be challenged (Townsend \& 
Marval, 2013; Wilding, 2011), such as taken-for-granted assumptions of who is responsible for knowledge production, a finding highlighted in this study.

\section{Implications}

Supporting practitioners in their commitment to praxis requires a professional occupational therapy culture which recognises critical praxis as equally essential to everyday practice as the technical skills that generally take priority (Hammell, 2020). It is hoped this would be reflected in the promotion of praxis (and its constituent parts) within occupational therapy education programs, ongoing educational opportunities for practitioners, and by professional registration bodies.

Mentoring, supervision, and/or communities of practice may be useful to support practitioners to remain praxis oriented. These could facilitate the critical reflexivity and dialogue essential for questioning taken-for-granted thoughts and actions (Wilding, 2011) and synthesising theory and practice, and may be fruitful areas for future research.

Participants highlighted for them, critical perspectives had come from additional studies outside of occupational therapy. If occupational therapists are to be critical practitioners capable of advancing a social justice agenda (World Federation of Occupational Therapists, 2016) then such critical perspectives need to be cultivated within standard occupational therapy education and ongoing professional development. Students and practitioners should be encouraged to question, critique and build on theory in light of their own realities, questioning their own positionality and taken-for-granted assumptions about the world and occupational therapy (Hammell, 2020). This would assist them to develop critical thinking and reflexivity, providing preliminary lessons in the cyclical process of praxis (Freire et al., 2014). Furthermore, integrating critical social theory into occupational therapy education and professional development could provide theoretical foundations for interrogating practice and developing critical perspectives required for working in the social 
field (Irvine-Brown et al., 2020). Such critical perspectives would continue to serve practitioners (and their clients) in multiple practice contexts long after the content they have learnt becomes redundant (Hammell, 2020). Exploring whether/how occupational therapy programs and professional development bodies are already doing this would be a worthwhile area for future research.

\section{Limitations}

A limitation of this study was its sample size, believed to be due to the niche area of practice and challenges reaching potential participants. However, we believe the findings display trustworthiness relative to the small sample size, as we followed widely accepted qualitative research strategies to ensure a rigorous approach to data collection and analysis (Nowell et al., 2017). Nevertheless, the findings are exploratory in nature and need further confirmation through future research. Additionally, the study design may have been a limitation because praxis may often be an internal and implicit process, which this study sought to explore through explicit dialogical processes. Observing practitioners in practice may have provided opportunities to make explicit the implicit and facilitate a deeper exploration of praxis.

\section{Conclusion}

This study aimed to explore whether and how Australian occupational therapycommunity development practitioners are engaging in critical praxis. These initial findings suggest occupational therapy-community development practitioners are capable of engaging in critical praxis but need greater support in both foundational education, and in an ongoing capacity by the profession-at-large, to do so effectively and consistently.

\section{Key Messages}

- Occupational therapists are capable of engaging in critical praxis to promote more responsive actions aimed at social transformation. 
- Occupational therapists require support to develop, use and maintain skills in critical praxis to be effective in responding to the complexities of their context.

- More research is needed to understand how to better support occupational therapists navigating tensions of working towards social transformation. Investigating the effectiveness of a community of practice to do this may be worthwhile.

\section{Declaration of Interest Statement}

The authors declare no conflict of interest.

\section{References}

Babbie, E. R. (2015). The Practice of Social Research. Cengage Learning US. http://ebookcentral.proquest.com/lib/griffith/detail.action?docID=4458812

Berger, R. (2013). Now I see it, now I don't: Researcher's position and reflexivity in qualitative research. Qualitative Research, 15(2), 219-234. https://doi.org/10.1177/1468794112468475

Braun, V., \& Clarke, V. (2006). Using thematic analysis in psychology. Qualitative Research in Psychology, 3(2), 77-101. https://doi.org/10.1191/1478088706qp063oa

Farias, L., \& Laliberte Rudman, D. (2019a). Challenges in enacting occupation-based social transformative practices: A critical dialogical study. Canadian Journal of Occupational Therapy, 1-10. https://doi.org/10.1177/0008417419828798

Farias, L., \& Laliberte Rudman, D. (2019b). Practice analysis: Critical reflexivity on discourses constraining socially transformative occupational therapy practices. British Journal of Occupational Therapy, 82(11), 693-697. https://doi.org/10.1177/0308022619862111

Farias, L., Laliberte Rudman, D., \& Magalhães, L. (2016). Illustrating the importance of critical epistemology to realize the promise of occupational justice. OTJR: Occupation, Participation and Health, 36(4), 234-243. https://doi.org/10.1177/1539449216665561 
Farias, L., Laliberte Rudman, D., Pollard, N., Schiller, S., Serrata Malfitano, A. P., Thomas, K., \& van Bruggen, H. (2019). Critical dialogical approach: A methodological direction for occupation-based social transformative work. Scandinavian Journal of Occupational Therapy, 26(4), 235-245.

https://doi.org/10.1080/11038128.2018.1469666

Freire, P. (1972). Pedagogy of the oppressed. Penguin Books.

Freire, P., Freire, A. M. A., de Oliveira, W., \& Giroux, H. A. (2014). Pedagogy of Solidarity. Taylor \& Francis.

http://ebookcentral.proquest.com/lib/griffith/detail.action?docID=1674127

Galvaan, R. (2017). Occupation-based community development: A critical approach to occupational therapy. In A. Dsouza, R. Galvaan, \& E. Ramugondo (Eds.), Concepts in occupational therapy: Understanding Southern perspectives (pp. 172-187). Manipal University Press.

Hammell, K. W. (2020). Engagement in living: Critical perspectives on occupation, rights, and wellbeing. Canadian Association of Occupational Therapists.

Hammell, K. W., \& Iwama, M. K. (2012). Well-being and occupational rights: An imperative for critical occupational therapy. Scandinavian Journal of Occupational Therapy, 19(5), 385-394. https://doi.org/10.3109/11038128.2011.611821

Hocking, C. (2017). Occupational justice as social justice: The moral claim for inclusion. Journal of Occupational Science, 24(1), 29-42. https://doi.org/10.1080/14427591.2017.1294016

Hyett, N., Kenny, A., \& Dickson-Swift, V. (2018). Re-imagining occupational therapy clients as communities: Presenting the community-centred practice framework. Scandinavian Journal of Occupational Therapy, 1-15. https://doi.org/10.1080/11038128.2017.1423374

Ife, J. (2016). Community development in an uncertain world: Vision, analysis \& practice (2nd ed.). Cambridge University Press. 
Ingamells, A. (2010). Community development: Traditions of practice and contemporary contexts. In A. Ingamells, A. Lathouras, R. Wiseman, P. Westoby, \& F. Caniglia (Eds.), Community development practice: Stories, method \& meaning (pp. 1-9). Common Ground Research Networks. https://doi.org/doi:10.18848/978-1-86335-6466/CGP

Irvine-Brown, L., Di Tommaso, A., Malfitano, A. P. S., \& Molineux, M. (2020). Experiences of occupational therapy education: Contexts, communities and social occupational therapy. Brazilian Journal of Occupational Therapy, 28(1), 330-342.

https://doi.org/10.4322/2526-8910.ctoARF1931

Kincheloe, J., \& McLaren, P. (2000). Rethinking critical theory and qualitiative research. In k. hayes, S. R. Steinberg, \& K. Tobin (Eds.), Key works in critical pedagogy (2nd ed., pp. 279-314). Sage Publications.

Kinsella, E. A. (2001). Reflections on reflective practice. Canadian Journal of Occupational Therapy, 68(3), 195-198. https://doi.org/10.1177/000841740106800308

Kinsella, E. A., \& Whiteford, G. (2009). Knowledge generation and utilisation in occupational therapy: Towards epistemic reflexivity. Australian Occupational Therapy Journal, 56, 249-258. https://doi.org/10.1111/j.1440-1630.2007.00726.x

Ledwith, M. (2016). Community development in action: Putting Freire into practice. Policy Press.

Ledwith, M., \& Springett, J. (2010). Participatory justice: Community based action for transformative change. The Policy Press.

Lenette, C., \& Ingamells, A. (2015). Mind the Gap! The growing chasm between fundingdriven agencises, and social and community knowledge and practice. Community Development Journal, 50, 88-103. https://doi.org/10.1093/cdj/bsu024

Lopes, R. E., \& Malfitano, A. P. S. (2021). Social occupational therapy: Theoretical designs and practical outlines. Elsevier.

Malfitano, A. P. S., \& Lopes, R. E. (2018). Social occupational therapy: Committing to social change. New Zealand Journal of Occupational Therapy, 65(1), 20-26. 
Newing, H., Eagle, C. M., Puri, R. K., \& Watson, C. W. (2011). Conducting research in conversation: A social science perspective. Routledge.

Nowell, L. S., Norris, J. M., White, D. E., \& Moules, N. J. (2017). Thematic analysis: Striving to meet the trustworthiness criteria. International Journal of Qualitative Methods, 16, 1-13. https://doi.org/10.1177/1609406917733847

Pollard, N., \& Sakellariou, D. (2017). Occupational thearpy on the margins. World Federation of Occupational Therapists Bulletin, 73(2), 71-75. https://doi.org/10.1080/14473828.2017.1361698

Purcell, R. (2011). Community development and everyday life. Community Development Journal, 47(2), 266-281. https://doi.org/10.1093/cdj/bsq058

Quiroga, D. M. O., \& Reyes, M. S. (2019). Occupational therapy with the communtiy: Complexity, actions, and contexts. Brazilian Journal of Occupational Therapy, 27(1), 197-207. https://doi.org/10.4322/2526-8910.ctoRE1715

Sen, A. (1999). Development as freedom. Oxford University Press.

Shaw, M. (2017). Community development: Reviving critical agency in times of crisis. In S. Kenny, B. McGrath, \& R. Phillips (Eds.), The Routledge handbook of community development (1st ed., pp. 26-39). Routledge. https://doi.org/10.4324/9781315674100

Townsend, E., \& Marval, R. (2013). Can professionals actually enable occupational justice? Brazilian Journal of Occupational Therapy, 21(2), 215-228. https://doi.org/10.4322/cto.2013.025

Westoby, P. (2014). Theorising the practice of community development: A South African perspective [Electronic Book]. Routledge. https://doi.org/10.4324/9781315551227

Westoby, P., \& Ingamells, A. (2012). Teaching community development personal practice frameworks. Social Work Education, 31(3), 383-396.

https://doi.org/10.1080/02615479.2010.550913 
Whiteford, G., Jones, K., Rahal, C., \& Suleman, A. (2018, 2018/10/02). The Participatory Occupational Justice Framework as a tool for change: Three contrasting case narratives. Journal of Occupational Science, 25(4), 497-508.

https://doi.org/10.1080/14427591.2018.1504607

Whiteford, G., Townsend, E., Bryanton, O., Wicks, A., \& Pereira, R. B. (2017). The participatory occupational justice framework: Salience across contexts. In D. Sakellariou \& N. Pollard (Eds.), Occupational therapies without borders: Integrating justice with practice (2nd ed., pp. 163-174). Elsevier.

Wilding, C. (2011). Raising awareness of hegemony in occupational therapy: The value of action research for improving practice. Australian Occupational Therapy Journal, 58(4), 293-299. https://doi.org/10.1111/j.1440-1630.2010.00910.x

World Federation of Occupational Therapists. (2016). Minimum standards for the education of occupational therapists. https://www.mailmens.nl/files/21072349/copyrighted+world+federation+of+occupati onal + therapists + minimum + standards + for + the + education + of + occupational + therapists +2016a.pdf 